\title{
Políticas Sociais e Ajuste Econômico: \\ a América Latina na Década de 1990
}

\author{
Julio Manuel Pires
}

Resumo: Ao longo da década de 1990, os países da América Latina promoveram alterações importantes em suas políticas econômicas associadas, sobretudo, à busca da estabilidade monetária, com impactos importantes sobre a política fiscal e a política social. 0 artigo busca examinar alguns aspectos relevantes associados às principais modificações operadas na política social dos países latino-americanos na década de 1990. Destaque particular é emprestado às políticas na área de saúde - e, associadas a elas, às propostas do Banco Mundial - e à questão da eqüidade.

Palavras-chave: Política Social, América Latina, Políticas de Saúde, Estado, Neoliberalismo.

Abstract: In the course of 1990', Latin American countries promote significant changes in their economic policies with the essential purpose of price stabilization. These policies had important impacts upon fiscal policy and social policy. The article aims analyze some important features about main modifications of the Latin American countries' social policy in the 1990’. The analysis emphasizes the health policies - and the World Bank's proposals - and the problem of equity.

Keywords: Social Policy, Latin América, Health Policies, State, Neoliberalism.

\section{Introdução}

Constitui-se fato evidente a qualquer pessoa minimamente informada a péssima distribuição de renda característica de grande número de países latino-americanos ${ }^{1}$,

\footnotetext{
Professor Doutor do Departamento de Economia da Faculdade de Economia, Administração e Contabilidade de Ribeirão Preto da Universidade de São Paulo (FEARP-USP) e do Departamento de Economia e do Programa de Estudos Pós-Graduados em Economia Política da Pontifícia Universidade Católica de São Paulo (PUC-SP). E-mail: jmpires@usp.br

${ }^{1} 0$ índice de Gini para a América Latina nos anos 1990 (próximo a 0,6) apresentava-se mais elevado que 0 africano (inferior a 0,5) e bem maior que das demais regiões do globo: Ásia, EUA/Canadá/Austrália e Europa, cujos coeficientes de Gini eram inferiores a 0,35. Para mais detalhes veja-se Deininger \& Squire (1996) No contexto latino-americano - é importante mencionar - competem a países como Brasil, Honduras, Guatemala, Chile, Panamá e México, os piores indicadores.
} 
assim como a persistência de altos níveis de pobreza relativa e absoluta. Também tem sido documentada pela literatura pertinente a contribuição muito modesta ou mesmo negativa facultada pela política social a esta situação. Ou seja, quando se consideram as fontes de receita e os gastos relacionados à área social, o resultado, no mais das vezes, tem sido o agravamento do quadro distributivo e não sua amenização.

Ninguém ignora também o fato da política social, em nossos dias - e isto já há algumas décadas - constituir parcela importante da vida de todos os indivíduos. Tornou-se praticamente impossível imaginar o funcionamento das sociedades modernas sem a presença de todo o aparato institucional próprio da intervenção no campo social. A profusão dessas instituiçôes acabou por moldar todo um sistema diferenciado e complexo de relacionamento entre a sociedade e o Estado, constituindose como fundamental para a regulação do sistema econômico como um todo. Ademais, as cifras correspondentes aos gastos governamentais na denominada área social alcançam, na maioria dos países, porcentagens significativas do produto interno bruto.

As carências materiais vivenciadas por parcela majoritária da população latinoamericana são imensas. Tornou-se comum a referência ao descompasso entre o desenvolvimento no campo econômico e social. Por certo, tal estado de coisas tem a ver também com o nível ainda incipiente de desenvolvimento econômico alcançado pela economia latino-americana. Se a renda per capita for tomada como indicador aproximado de produtividade, percebemos claramente a posição desvantajosa da América Latina no cenário internacional. Todavia, isto não explica tudo. Encontrase isenta de polêmica a afirmativa de que a produção por habitante em nosso subcontinente, ainda que relativamente modesta, daria conta de proporcionar melhores condiçôes de vida à maioria da população, caso outros condicionantes sócio-políticos estivessem presentes.

Consentânea com tal assertiva, tem-se a constatação de que os Estados nos países da América Latina já se revelam capazes de apropriarem-se de parcela significativa do excedente econômico gerado. $\mathrm{O}$ evolver da despesa governamental como porcentagem do PIB nas últimas décadas demonstra a ampliação do raio de manobra do setor público e a possibilidade de canalização de parte do excedente para a política social, conseguindo-se, dessa forma, desempenho superior no que tange aos indicadores de qualidade de vida.

Vários países com níveis de desenvolvimento econômico semelhantes e mesmo inferiores ao do Brasil e de nossos vizinhos latino-americanos, no entanto, apresentam desempenho superior no tocante aos diversos indicadores possíveis de ser utilizados para apreciação da qualidade de vida da maioria da população (taxa de alfabetização, esperança de vida ao nascer, taxa de mortalidade infantil etc.). E a referência aqui 
não é a variações de pequena monta. As significativas diferenças percentuais encontradas nos indicadores supracitados significam, concretamente, milhares ou mesmo milhões de pessoas sem acesso à educação básica, morrendo antes de completar um ano de vida ou deixando de usufruir de uma longevidade maior, quando a situação poderia, considerados apenas os parâmetros econômicos, ser bem diferente.

A política social pode vir a desempenhar papel crucial nestes indicadores, seja para acirrar o estado de carência de parcela significativa da população quando de sua ausência ou ineficiência, ou ainda para atenuar as condiçôes impostas pelo contexto econômico mais amplo, quando conduzida no sentido de corrigir os efeitos mais perniciosos do mercado. As possibilidades de sua colaboração para o aumento do bem-estar social são imensas.

Sabemos que, historicamente, o desempenho dos estados latino-americanos no tocante à política social não tem apresentado o desempenho que dela se esperava. A relativa debilidade do gasto social nos países latino-americanos encontra-se relacionado a diversos fatores, entre os quais podemos citar (Avelino Filho, Brown \& Hunter, 2002: 8): a relativa fragilidade do movimento sindical e do Estado ${ }^{2}$, a quase inexistência de partidos social-democratas, a carência de fatores históricos voltados para políticas de proteção universalistas e de solidariedade social.

Por outro lado, quando se considera os principais condicionantes do evolver das políticas públicas nas últimas décadas, não há como descurar a "transição" efetuada de forma quase unânime nas diversas nações entre o modelo de políticas sociais e o padrão de gastos públicos a ele relacionado vigente até os anos 1970/1980 - fortemente vinculado ao Welfare State keynesiano (no caso dos países desenvolvidos) ou às políticas desenvolvimentistas (países periféricos) - e a necessidade de ajuste econômico de caráter liberal que se impôs a todos os países nos anos 1980/1990, com reflexos significativos sobre a estrutura institucional, o padrão de financiamento e o volume de recursos despendidos com a política social.

A questão que se impõe a partir das reflexões sumarizadas acima é a seguinte: será que a experiência de estruturação, condução e "transição" das políticas sociais de outros países, sobretudo latino-americanos, não poderia servir como contraponto

\footnotetext{
Relativamente a este aspecto, Avelino Filho, Brown \& Hunter (2002:9) apontam para o fato de que "governments in the region are notorious for their inability to carry out some of the most essential tasks - such as the collection of tax revenues - for supporting generous welfare states".
} 
importante para a análise da política social brasileira, visando aperfeiçoá-la em seus diversos aspectos?

Não se trata aqui, é importante notar, de simplesmente tomar a experiência internacional como modelo a ser seguido, nada mais distante de nossa perspectiva. O que na verdade está sendo proposto é a construção de uma visão mais abrangente a respeito das possibilidades de estruturação e transformações das políticas sociais em um momento de transição fundamental vivenciado pelas economias e pelos Estados nacionais, tendo em vista a visualização de eventuais alternativas mais consistentes e adequadas e mesmo o aprendizado com os erros alheios, com o intuito de não reproduzi-los.

O objetivo deste trabalho, portanto, é traçar um panorama amplo das principais modificações operadas no âmbito das políticas sociais nos países latino-americanos durante a década de 1990, tendo como pano de fundo as políticas de estabilização e liberalização implementadas nesse período. Particular atenção será dada - à guisa de exemplo - às políticas de saúde e aos aspectos relacionados à eqüidade no financiamento das políticas sociais. Compõe também o escopo deste artigo a análise das proposições emanadas do Banco Mundial, dado seu relevante papel no tocante ao financiamento dos gastos na área de saúde de alguns países latino-americanos.

\section{Reformas Econômicas e Impactos sobre a Política Social}

Ao longo das décadas de 1980 e 1990, grande parte dos países latino-americanos passou por um processo de liberalização comercial e nos mercados de capitais e serviços jamais experimentado por estas naçōes. A crise da dívida, no início dos anos 1980, e a necessidade de buscar a estabilização de preços no final dessa década e início dos anos 1990, condicionou de forma bastante significativa a política econômica relativa ao setor externo ${ }^{3}$. Há que se destacar, nesse contexto, o papel privilegiado desempenhado pelo Fundo Monetário Internacional (FMI) na definição das linhas mestras de ajustamento das políticas macroeconômicas.

Conquanto possam ser identificados impactos positivos relativamente a diversos aspectos da vida econômica dos países da América Latina - como a estabilidade monetária e a melhoria das condiçôes gerais de competitividade internacional -, as conseqüências perversas desse processo de liberalização externa sobre amplos

\footnotetext{
${ }^{3}$ Duas exceções importantes a essa constatação referem-se aos casos do Chile e da Argentina, os quais iniciaram suas políticas de liberalização comercial após os golpes militares sofridas por estas nações em meados da década de 1970.
} 
segmentos populacionais é inegável. Isso ocorreu, sobretudo em virtude do aumento da desigualdade social, do desemprego e do subemprego.

Em vista desse quadro, os governos de cada país viram-se constrangidos a tentar conciliar duas alternativas, a princípio, divergentes no que diz respeito à política fiscal: a busca de maior eficiência e a tentativa de proteger os grupos sociais mais diretamente atingidos, mediante políticas compensatórias, sobretudo por meio da expansão do gasto social.

A primeira alternativa, voltada fundamentalmente para a redução de custos, por meio da constituição de um Estado "mais enxuto" baseia-se na necessidade de ampliar o grau de competitividade da economia como um todo.

"The central notion of the efficiency approach is that governments will reduce taxes and social welfare expenditures that diminish profits, discourage investments, and therefore threaten economic growth and international competitiveness. Social services burden business through the distortion of labor markets and higher taxes (...) In short, the efficiency approach envisions economic openness as pitting efficiency harshly against welfare, and leaving governments little choice but to restrict their social outlays" (Avelino Filho, Brown \& Hunter, 2002: 5-6).

Trata-se, portanto, de, entre outras medidas associada a este linha de pensamento, sacrificar os gastos sociais em prol da maior eficiência da economia - exigida pelo novo contexto de maior abertura comercial e financeira.

A visão alternativa passa pelo reconhecimento de que este novo contexto impõe a todos os países maiores restriçôes à gestão de suas economias, deixando-os muito expostos às oscilaçôes da economia mundial e daí a necessidade de adoção mais enfática de políticas compensatórias para os grupos sociais mais vulneráveis.

"The compensation perspective recognizes the constraints imposed by economic integration on the social policy options of governments, yet accords weight to the countervailing demands imposed by citizens seeking protection from the state. It stresses the perception among top elected officials and bureaucrats that social instability and political discontent engendered by internationalization could ultimately endanger the model of economic openness as well as their careers. The core contention of the compensation thesis is that government officials use the latitude they have to strengthen social insurance mechanisms and cushion citizens from the vagaries of the international economy" (Avelino Filho, Brown \& Hunter, 2002: 6).

A partir desse quadro de opçôes, uma questão que naturalmente se impõe aos pesquisadores da área diz respeito ao tipo de reação dos governos nacionais às injunções de uma economia mais aberta: será que a opção majoritária se fez pela busca de 
maior eficiência ou pela adoção de políticas compensatórias. O trabalho de Avelino Filho, Brown \& Hunter (2002) busca responder a esta questão com relação aos países da América Latina. Por meio de um modelo econométrico, os autores buscam estimar qual impacto foi mais relevante para dezenove países analisados ${ }^{4}$. Além disso, também são examinados quais os fatores mais relevantes para explicar a variação do gasto social entre 1980 e 1997, destacando-se o maior ou menor grau de abertura comercial e financeira da economia e o regime político do país (democracia ou ditadura). As conclusōes alcançadas pelos autores apontam no sentido de um impacto negativo da abertura econômica sobre o gasto social, seja em termos per capita seja como porcentual do produto interno bruto ${ }^{5}$, e de um impacto positivo dos regimes democráticos (vis-à-vis os regimes autoritários) sobre o gasto social. Nesse último caso, os resultados apontam que "the difference between democratic and authoritarian regimes is roughly .8 percentage points of GDP per capita" (Avelino Filho, Brown \& Hunter, 2002: 18).

Uma outra constatação importante do mesmo trabalho é que o impacto mais favorável proveniente da instituição de regimes democrático fez-se, sobretudo, sobre as despesas com educação, enquanto os dispêndios com saúde foram os mais fortemente atingidos, negativamente, pela abertura econômica, ainda que os gastos com educação também tenham sido afetados de forma desfavorável.

A expansão acentuada dos fluxos internacionais de capitais e a dependência crescente desses recursos externos por parte da grande maioria dos países teve como uma de suas principais conseqüências a imposição de controles mais rigorosos sobre as contas públicas. No caso dos países latino-americanos, as características peculiares assumidas pelas estratégias de estabilização econômica, implementadas desde o final dos anos 1980, magnificou tal relação de dependência.

Tal restrição repercutiu, no âmbito das políticas sociais, sob a forma do privilégio cada vez maior emprestado às políticas de focalização dos programas sociais. Esta mudança de referencial nos anos 1990, comparativamente à proposta de universalização que caracterizou as décadas anteriores, encontra-se relacionada não só à busca de redução do dispêndio público como um todo, mas também ao diagnóstico de baixa efetividade e grande iniqüidade do sistema de proteção social dos países latino-americanos.

\footnotetext{
${ }^{4}$ Os dezenove países considerados são: Argentina, Bolívia, Brasil, Chile, Colômbia, Costa Rica, República Dominicana, El Salvador, Guatemala, Honduras, Jamaica, México, Nicarágua, Panamá, Paraguai, Peru, Uruguai e Venezuela. ${ }^{5}$ Tais resultados vêm confirmar trabalho anterior realizado por Kaufman \& Segura (2001), abrangendo um período de tempo maior. É importante observar que, para os países da OECD, os resultados apontam no sentido contrário, ou seja, a abertura comercial fez-se acompanhar por uma ampliação relativa do dispêndio social.
} 
As consequêencias de tais políticas foram a fragmentação da política social, inibindo-se a caracterização dos direitos sociais como garantias universais, na medida em que se promove um acesso diferenciado das pessoas ao usufruto dos direitos à saúde, educação, previdência social etc., privilegiando-se o critério de capacidade de pagamento.

Quando se considera especificamente o caso brasileiro, não resta qualquer dúvida quanto aos resultados diametralmente opostos sobre a dinâmica da política social dos dois ciclos de reformas das políticas sociais por que passou o Brasil nos anos 1980 e 1990 ( Draibe, 2002). Como resultado do processo de redemocratização e de reorganização do Estado e das políticas públicas brasileiras nos anos 1980, vislumbramos uma inequívoca ampliação do escopo das políticas públicas, cujo cerne era a ampliação dos grupos beneficiados e o direcionamento para a universalização.

"As várias tentativas de políticas de estabilização e ajuste macroeconômico produziram impactos residuais sobre o sistema de proteção social, e nos indicadores de acesso e utilização de serviços sociais. As tradiçōes organizacionais das políticas setoriais e as exigências do sistema político democrático recém instituído foram as variáveis institucionais que permitiram ao setor social uma impermeabilidade diante das bruscas alteraçôes de cenários macroeconômicos. Pode-se verificar que na década de 1980, não houve uma descontinuidade no crescimento da proteção social: foi expandido o gasto público e adotados critérios universalistas para definição de direitos. Esse incremento na incorporação de novas clientelas ao sistema de proteção social foi formalizado na Constituição de 1988" (Costa, 2002: 17).

Nos anos 1990, sobretudo a partir de meados da década, a ênfase nas políticas sociais se altera de forma importante, ganhando maior espaço as políticas focalizadas. Todavia, não é possível esquecer, que, a despeito desse novo contexto, há uma certa inércia das mudanças operadas no período anterior (anos 1980) que irá se estender no período seguinte, algumas delas diretamente vinculadas à ampliação de direitos consolidados na Constituição.

\section{Novas Tendências no Gerenciamento da Política Social}

Uma outra característica importante no tocante às mudanças experimentadas pela política social na América Latina nos anos 1990 diz respeito à tendência crescente ao "processo de mercantilização dos serviços sociais" (Fleury, 2002: 4), com a transferência cada vez maior de parcelas dos serviços de saúde, educação e previdência social, antes reservados ao setor público, para o setor privado. Isto fez com que a 
lógica do lucro e da expansão do mercado, isto é, tratamento da oferta desses serviços como mercadorias, se sobrepusesse cada vez mais à idéia de solidariedade social.

Essa predominância crescente da lógica do lucro revelou-se de forma mais contundente na expansão dos seguros privados nas áreas de saúde e previdência social, conquanto a expansão do setor privado na área de ensino também não possa ser menosprezada.

Um outro aspecto dessas mudanças refere-se ao papel cada vez mais proeminente emprestado às Organizações Não Governamentais na execução das políticas públicas. O denominado Terceiro Setor viu, assim, ampliar de forma significativa seu papel como operador das políticas públicas.

Trata-se, na verdade, de "uma nova forma de administrar o problema da 'questão social', no qual o Estado sai gradativamente do oferecimento de serviços para dar margem à intervenção empresarial e ao terceiro setor, em especial, as ONGs" (Cavalcanti, 2001: 10).

Tal importância ampliada das ONGs constitui parte de um contexto maior, caracterizado pela crise fiscal do Estado ${ }^{6}$, o qual deu ensejo a uma nova perspectiva sobre as formas de enfrentamento dos problemas sociais. Trata-se agora, de repartir a responsabilidade no tocante às "questôes sociais" com a sociedade civil e com o setor empresarial. Admite-se, portanto, que "o Estado, é assim, incapaz de resolver esses impasses que se agravam ao longo dos anos e décadas, devendo, portanto, seu ônus ser dividido com a sociedade como um todo. Aqui converge a idéia de solidariedade com os menos favorecidos, já que o Estado não é capaz de garantir direitos sociais para todos" (Cavalcanti, 2001: 25) ${ }^{7}$.

\footnotetext{
${ }^{6}$ A visão sintética do então Ministro da Administração e Reforma do Estado, Luiz Carlos Bresser Pereira, é elucidativa a este respeito: " 0 Estado entrou em crise e se transformou na principal causa de redução das taxas de crescimento econômico, da elevação das taxas de desemprego e do aumento da taxa de inflação, que desde então, ocorreram em todo o mundo". Bresser Pereira, Luiz Carlos. A reforma do Estado nos anos 90: lógica e mecanismos de controle. Brasília: MARE, 1997, Cad. 01, 57 p. Apud Cavalcanti, 2001: 17.

${ }^{7}$ É importante notar que tais mudanças não ficaram restritas aos países em desenvolvimento. Relativamente aos países desenvolvidos, pertencentes à OCDE, pode-se verificar a ocorrência de algumas mudanças importantes no âmbito das políticas sociais: 1) ampliação do escopo das políticas públicas seletivas, com a utilização mais intensa de testes de meio e o estabelecimento de regras mais estreitas de elegibilidade; 2) transferência de responsabilidade para o setor privado; e 3) mudanças nas regras de definição dos benefícios, caracterizadas, em geral, por reduções no valor e/ou aumento do grau de exigência para o recebimento (por exemplo, aumento do número de anos de contribuição para aposentadoria). (Pierson, "The new politics of welfare state". In: The Welfare State: A Reader. Cambridge: Blackwell Publishers, 2000, p. 300-319. Apud Costa, 2002: 14-16)
} 
É importante frisar que, em meio a esse conjunto de reformas, algumas questões permaneceram intocadas. Um dos problemas centrais que ainda perpassa as políticas públicas nos países latino-americanos, notadamente na área social, diz respeito às estruturas administrativas patrimoniais e clientelistas. Observa-se ainda, em diversos contextos, a dificuldade no estabelecimento pleno do conceito de cidadania. "A igualdade implícita na cidadania requer a existência de critérios impessoais, objetivos e universais na distribuição de recursos públicos, muitas vezes negada, em sociedades onde predomina uma cultura patrimonialista, onde os recursos públicos são apropriados de forma privada e/ou são distribuídos como troca de favores na barganha política" (Fleury, 2002: 6).

O setor de saúde constitui um ótimo exemplo das principais transformações ocorridas no âmbito das políticas sociais, sendo, por conseguinte, examinado no próximo tópico.

\section{As Reformas na Área de Saúde e o Papel do Banco Mundial}

As principais críticas que se fazem normalmente aos sistemas públicos de saúde latino-americanos encontram-se vinculadas à sua reduzida cobertura, baixa qualidade e ineficiência administrativa (Bustelo, 1994:25). Ao longo dos anos 1980, tais problemas viram-se agravados pela maior demanda dos serviços públicos de saúde por parte de amplos segmentos populacionais, incapazes de fazer frente aos gastos privados com estes serviços, por conta do desemprego e/ou da queda de renda.

No que respeita à qualidade dos serviços médicos ofertados pelo setor público, há que se destacar também a colaboração decisiva emprestada pelo processo de deterioração dos salários dos profissionais da área, o que redundou também em aumento do número de greves, prejudicando sobremaneira os usuários do sistema.

As despesas associadas ao setor saúde têm no condicionante demográfico um de seus principais determinantes. Países com elevada proporção de população idosa apresentam pressões maiores de custo sobre os sistemas de saúde. Se agregarmos a isso a alta e crescente densidade tecnológica utilizada na área de saúde - tanto em relação ao diagnóstico quanto à terapia - teremos aí parcela importante da explicação das pressóes crescentes de custos na área de saúde com que se deparam todos os países (Misoczky, 2003: 1).

Um outro problema ainda pendente refere-se ao privilégio dado no âmbito do orçamento público ao gasto com saúde curativa em detrimento da saúde preventiva. É relativamente comum observar uma maior alocação relativa de recursos públicos para $\mathrm{a}$ área de atendimento médico individualizado em detrimento da aplicação na área de saúde pública, a despeito da maior eficiência associada a este último tipo de dispêndio. 
"Tal situación se explica porque em general los servicios de salud publica puros no tienen demanda explícita por parte de los consumidores y no generan recuperación de costos (deberían ser gratuitos), en cambio los servicios clínicos (medico-hospitalarios en general) si tienen demanda explícita individual y pueden generar recuperación parcial de costos. Cuando el proveedor de servicios tiene a su cargo unos servicios con demanda y otros sin demanda generalmente priorizará aquellos que tienen mas demanda aunque no sean los mas costo-eficientes”. (Pérez, 2002: 7).

Visando fazer frente a tais questões, várias propostas foram elaboradas pelos diversos governos com a colaboração ou "inspiração" de organismos internacionais como o Banco Mundial.

As características principais das propostas de reformas dos sistemas de saúde ao longo dos anos 1990 podem ser resumidas em quatro pontos principais: descentralização do Estado, surgimento de novos atores públicos e privados no setor, desconcentração/descentralização dos serviços de saúde e separação de funções.

Mais especificamente, segundo Prosperi (2000), os princípios que orientaram as reformas do setor saúde na América Latina foram os seguintes:

1) Fomentar a eqüidade em relação à saúde, tanto no que diz respeito ao acesso e uso dos serviços quanto em relação ao financiamento dos mesmos;

2) Aumentar a eficiência dos gastos em saúde e a dotação e gestão dos recursos;

3) Assegurar a sustentabilidade tanto no tocante à legitimidade quanto no que se refere ao financiamento;

4) Incentivar a participação social no planejamento, na gestão, na oferta e na avaliação e;

5) Melhorar a qualidade da atenção, do ponto de vista técnico e do ponto de vista do usuário.

Relativamente ao novo papel a ser exercido pelo Estado na área de saúde e a repartição de responsabilidades entre os níveis de governo e o setor privado, a citação seguinte, de Pérez, reproduzindo as propostas do Banco Mundial são bastante elucidativas do pensamento dominante na década de 1990.

"La redefinición del rol del Estado en el mundo, obliga a pensar en una administración pública más pequeña, descentralizada y actuando en asocio con el sector privado. Dentro del nuevo contexto el gobierno nacional debe delegar en el sector privado y en las entidades subnacionales aquellas competencias en las cuales es menos eficiente y eficaz e identificar cuales son aquellas funciones que son indelegables y que le competen por su naturaleza misma. Para el caso de la salud el Estado debe redefinir el espacio propio que le corresponde a la Salud Pública 
desligándola de los servicios que pueden ser provistos mas eficazmente por el mercado. Debe entenderse entonces que para los efectos de ejercer las funciones esenciales de Salud Pública al Estado siempre le compete regular los servicios de salud y en forma permanente garantizar con sus recursos propios la provisión de servicios de beneficio com ún y de altas externalidades". (Pérez, 2002: 4).

As proposições do Banco Mundial para a área de saúde não podem ser vistas como meros "conselhos/recomendaçôes", sem qualquer efeito prático, uma vez que essa instituição constitui-se hoje numa das principais fontes de recursos externos do setor.

Apenas como exemplo da importância dos recursos fornecidos pelo Banco Mundial para os principais países da América Latina, cabe notar os números consolidados de empréstimos concedidos entre 1988 e 1998.

Tabela 1
Maiores Beneficiários de Financiamento
na Área de Saúde: 1988-1998
\begin{tabular}{|c|c|}
\hline País & US\$ milhões \\
\hline İndia & 2.777 \\
\hline México & 1.215 \\
\hline Brasil & 935 \\
\hline Argentina & 691 \\
\hline China & 594 \\
\hline Bangladesh & 490 \\
\hline Indonésia & 445 \\
\hline Rússia & 336 \\
\hline Venezuela & 248 \\
\hline Nigéria & 244 \\
\hline
\end{tabular}

Fonte: Banco Mundial, 2002: 21

Como podemos observar na tabela acima, México, Brasil e Argentina só foram superados, em volume de recursos tomado emprestado, pela Índia, tendo esses três países superado nações com populações bem maiores, como é o caso da China, Indonésia, Rússia e Nigéria. Tal constatação reflete, de certa forma, um padrão de prioridade emprestada a esses países latino-americanos bastante elevado. 
No caso do Brasil, os principais projetos financiados foram: a Reforma do Setor Saúde - REFORSUS (US\$ 300 milhōes), o Programa de Controle de AIDS \& DST II (US\$ 165 milhōes) e o Projeto Vigilância Sanitária I - VIGISUS (US\$ 100 milhōes).

Nos dois primeiros anos do século XXI, o volume total de recursos alocados para empréstimos ao setor de saúde foi de aproximadamente US\$1,36 bilhôes. Tais recursos foram propiciados via Agência Internacional de Desenvolvimento (AID) e por meio do Banco Internacional de Reconstrução e Desenvolvimento (BIRD). Os recursos da AID somaram cerca de US\$ 750 milhões. São recursos altamente subsidiados (65\% a $80 \%$ constituem-se como doação, com prazo de pagamento de quarenta anos, podendo se candidatar países com PIB per capita menor que US\$ 1.446,00. Já os recursos do BIRD (cerca de US\$ 610 milhões) têm seu custo associado à Libor, com prazo de pagamento de quinze a vinte anos, podendo se candidatar países com PIB per capita menor que US\$ 5.225,00 (Banco Mundial, 2002: 24).

Dentre as principais recomendaçôes feitas pelo Banco Mundial aos países demandantes de recursos na área de saúde destacam-se a melhoria na capacidade de gerenciamento e de elaboração de políticas, o desenvolvimento de um sistema de informaçôes/coleta de dados mais adequado para a tomada de decisões, a maior descentralização de autoridade e a busca de uma ênfase maior na regulação em detrimento da regulação. Todas essas recomendaçōes, é importante observar, são feitas sem que se deixe de considerar o papel destacado que deve continuar a ter o setor público como responsável pelo gerenciamento total do setor saúde.

Nessa mesma linha de raciocínio, o Banco Mundial destaca o que ele considera elementos-chave para a reforma do setor saúde, com vistas a buscar uma maior eficiência, eqüidade e qualidade dos serviços prestados (Banco Mundial, 2002: 3233): associação de riscos (reduzindo-se a inequiidade e a segmentação da proteção financeira), garantia de nível adequado de financiamento para a saúde pública e para os serviços básicos para a população carente, contenção de custos e disciplina fiscal, maior transparência na alocação de recursos e práticas orçamentárias e, finalmente, desenvolvimento, testes e implementação de novos métodos de pagamento aos prestadores de serviços médicos.

No que tange diretamente à prestação dos serviços de saúde, o Banco Mundial trabalhou numa linha que enfatizava: a descentralização do gerenciamento, a separação entre a provisão e o financiamento (mudando-se a estrutura de incentivos, com o dinheiro seguindo o paciente e não sendo alocado diretamente para as unidades prestadoras do serviço) e a realização de parcerias entre sistemas públicos e privados.

Entre as experiências exitosas destacadas pelo Banco Mundial na América Latina, durante os anos 1990, pode-se citar: 
1) O Programa de AIDS no Brasil, por meio da utilização de Organizações não Governamentais, as quais, no período de uma década passaram de 200 para 600, conseguindo atingir efetivamente a maioria dos grupos afetados pela doença. Entre as atividades desenvolvidas por essas ONGs destacam-se o desenvolvimento de programas de troca de seringas, a distribuição de preservativos e a organização de grupos de apoio.

2) A extensão da cobertura básica ocorrida em alguns países da América Central (Guatemala, El Salvador e Panamá), também por meio de ONGs e de uma definição mais adequada da competência e responsabilidades do setor público, o que permitiu alcançar com maior efetividade os mais carentes e oferecer serviços de melhor qualidade.

3) O financiamento à demanda para serviços de saúde materno-infantil realizado no Peru e Bolívia. Mediante o Seguro Nacional de Maternidade e Infância, de caráter universal, foi possível aumentar a cobertura e a eficiência do sistema, instituindose o mecanismo de fazer o subsídio acompanhar o cliente quando da utilização de clínicas públicas. É importante observar que não se trata aqui de qualquer sistema de co-financiamento. Trata-se, na verdade de separar o financiamento da provisão, visando aumentar a resposta e a eficiência do sistema de saúde.

4) O programa de eqüidade da cobertura financeira levado adiante pelo governo colombiano, mediante o qual foi possível ampliar enormemente a cobertura de seguros, por meio de esquemas de contribuição e salários. Tal programa, cuja lei foi aprovada pelo Congresso Colombiano em dezembro de 1993, permitiu que a Colômbia, na avaliação da Organização Mundial da Saúde se situasse entre os países com maior eqüidade relativamente ao padrão de financiamento do setor. As linhas básicas do programa seguem as recomendaçōes do Banco Mundial, sobretudo no tocante à busca de "reorientar o gasto público para programas mais eficazes em termos de custos-focalização e critérios de custo-benefício", assim como quanto a "facilitar maior diversidade e competição do setor privado na prestação de serviços de saúde" (Misoczky, 2003: 2). Ao Estado coube fundamentalmente atender, por meio de investimentos diretos em programas básicos de saúde e em serviços clínicos essenciais, as populaçôes mais pobres ou residentes em regiôes escassamente povoadas. As pessoas com capacidade de contribuir, no momento em que necessitam de atendimento médico, podem optar por uma das instituiçôes certificadas como Empresa Promotora de Saúde (hospitais, consultórios, médicos, laboratórios), gerando, desse modo, competição entre elas. Também os hospitais públicos foram enquadrados nessa categoria, uma vez que foram transformados em Empresas Sociais do Estado, operando com base no direito privado e usufruindo de autonomia 
administrativa. O ponto desfavorável dessa reforma refere-se ao fato de que "os usuários são, então, tratados como clientes e submetidos aos mesmos critérios de inclusão de planos privados de seguro: inúmeras restrições, exclusão por condição pré-existente, limites de cobertura, complementação no pagamento no momento do atendimento" (Misoczky, 2003: 3).

5) O programa PAC/PROCEDES do México, voltado exclusivamente para a área rural, tratou de definir um "pacote básico" de serviços de saúde a serem oferecidos pelas estruturas públicas e cujos resultados positivos, segundo o Banco Mundial, são inequívocos.

\section{O Ambiente Institucional e as Formas de Financiamento}

Seguindo a linha de argumentação do Banco Mundial, uma das questôes primordiais levantadas nas reformas na área social - e particularmente na área de saúde - encontra-se relacionada às formas de financiamento dos dispêndios. A preocupação maior nesse caso consiste em aumentar a eficiência e a eqüidade dos sistemas de saúde. Nesse particular, algumas tendências de mudanças importantes podem ser observadas.

Uma questão essencial quando se discute a maior eficiência do gasto público na área de saúde diz respeito à criação de um ambiente institucional adequado para os gestores e trabalhadores do setor.

"Cuando el Estado garantiza la financiación fiscal de la oferta hospitalaria en forma independiente de su grado de productividad o calidad, está estimulando sin quererlo la pereza institucional de los hospitales, ya que no crea incentivos financieros para que los proveedores públicos busquen satisfacer y retener a los clientes, ampliar su cobertura o mejorar su calidad. En la misma forma cuando los funcionarios públicos poseen escalas de remuneración fijas tienden a reducir al mínimo su producción si no existen estímulos salariales o no salariales que premien la eficiencia, la productividad y el desempeño en el trabajo" (Pérez, 2002: 8).

Conquanto tais propostas tenham uma formulação geral fácil e relativamente consensual, sua operacionalização, levando-se em conta o risco de criar maiores distorçōes do que as já existentes, revela-se bastante problemática.

Uma das tentativas de melhorar a racionalização, a focalização e a eficiência do gasto público com saúde que se tem desenvolvido nos últimos anos aponta para a utilização de recursos públicos para a provisão de planos de benefícios para as populações mais pobres, substituindo o financiamento fiscal à oferta (provedores públicos ou privados) pelo financiamento à demanda da população mais pobre. 
Dessa forma, ao mesmo tempo em que se focaliza o gasto público, cria-se um ambiente concorrencial entre os prestadores de serviços de saúde que passam a ser obrigados a buscar a satisfação dos consumidores, mediante melhoria na qualidade do atendimento, aumento da produtividade e da cobertura.

Ao tratar do sistema de financiamento de saúde individualizada é possível inferir três possibilidades. A primeira delas é a forma de financiamento mediante o sistema de seguro social obrigatório, ou seja, contribuição compulsória por parte de patrões e empregados. Quando se considera tal forma de financiamento, em que pese alguns problemas específicos ${ }^{8}$, suas vantagens são bastante significativas, sobretudo quando consideramos seus aspectos distributivos. Não há, assim como descurar dos aspectos positivos associados a

"un sistema de contribución obligatoria basado en una tarifa de recaudo igual para todos los estratos socioeconómicos que garantiza los subsidios cruzados entre los grupos con altos ingresos y bajos riesgos o cargas familiares en beneficio de los contribuyentes de escasos ingresos y altos riesgos o cargas familiares. En la práctica el sistema financiero cuando existen monopolios de cobertura nacional garantiza la solidariedad entre regiones ricas y pobres y entre ramas de la producción más productivas con las menos productivas".

Além disso, uma outra vantagem bastante importante diz respeito à seleção adversa.

"Las contribuciones obligatorias se establecen com base al ingreso laboral y no con base al riesgo en salud lo cual permite que no se produzca selección adversa de los beneficiarios con riesgos mas costosos (crónicos, ancianos, maternas y niños) que por lo general son quienes tienen ingresos mas bajos dentro de sus estrato social. Los sistemas que cobran en proporción al riesgo (Chile, México, Estados Unidos y la medicina prepagada) generan necesariamente selección adversa de estos grupos sociales, incrementando el gasto familiar y fiscal en la protección de la salud o bien incrementando la morbilidad no atendida y la mortalidad" (Pérez, 2002: 9).

Uma outra alternativa, percorrida pelo Chile na década de 1980 - e em grande parte inspirada no modelo norte-americano - consiste em abandonar totalmente a idéia de solidariedade entre grupos com níveis de renda diferentes, risco associado e

\footnotetext{
${ }^{8}$ Os principais problemas apontados são as filas, as listas de espera, a baixa qualidade dos serviços prestados, os altos custos e a burocratização crescente. Pérez, 2002: 10).
} 
carga familiar, assim como deixando de lado qualquer pretensão relativa a um plano único de cobertura integral e obrigatória para todos os filiados.

"En este nuevo sistema cada cual compra un plan de contenido diverso según sea sua capacidad de pago y el costo de cada plan se corresponde con el valor pagado por el afiliado; en la práctica desaparece el sistema de contribuciones parafiscales para la financiación colectiva de la seguridad social y se crea un sistema de precios acorde a las reglas del mercado. Y es así que de un sistema en el cual: cada cual aportaba según su capacidad y recibía según su necesidad, se pasa a un sistema donde: cada cual paga de acuerdo al costo estimado de su riesgo atareo y de sus cargas familiares y recibe de acuerdo a su capacidad de pago. El nuevo sistema de mercado genera así todo tipo de selección adversa de los más pobres, de las maternas, los ancianos y los niños; genera además nuevas cargas fiscales a los Estados, porque estos tienen que cofinanciar la afiliación de los estratos medios de asalariados, responder por algunas prestaciones que generan selección adversa, como son los pagos por maternidad y en ultima instancia el fisco debe responder por los enfermos crónicos y de alto costo que son rechazados por el sistema privado" (Pérez, 2002: 10).

Todavia, é também possível pensar uma terceira alternativa, como a perseguida pela Argentina, que põe à disposição dos beneficiários um sistema de livre escolha entre várias seguradoras de saúde, mantendo-se, no entanto, à semelhança do seguro social obrigatório, a compulsoriedade da contribuição de todos os filiados na mesma proporção de seus salários, assim como um mesmo plano obrigatório de serviços médico-hospitalares. Além disso, previu-se também a criação de um fundo nacional de compensação e solidariedade entre as seguradoras com o intuito de equipará-las financeiramente em função do número de filiados de cada uma e ao custo per capita do plano integral obrigatório.

No entanto, é importante notar que a alternativa de transferir o financiamento fiscal da oferta para a demanda não significa eliminar, de uma vez por todas, a ineficiência do sistema. Vários problemas também se encontram associados à possibilidade do demandante, uma vez subsidiado pelo Estado, escolher quem lhe proverá os serviços de saúde. Um primeiro problema é a possível multiplicação de custos relacionada à solicitação de serviços médicos acima das reais necessidades por parte dos demandantes do sistema, dada a natural ansiedade associada aos estados mórbidos ou pretensamente mórbidos e a ausência de custos para o usuário. Nesse caso, a introdução de co-pagamentos e de cotas moderadoras costumam ser recomendadas.

Mas, outra forma, talvez mais importante para o aumento de custos do sistema, encontra-se relacionada à própria superestimativa de serviços necessários por parte dos provedores de serviços médicos, sejam hospitais ou profissionais autônomos. Isso pode 
ocorrer pela preferência por serviços mais caros - ainda que menos eficientes -, pela realização de exames ou práticas médicas desnecessárias e até mesmo pelo superfaturamento ou elevação artificial dos custos. A raiz desse problema, no entanto, se localiza na dificuldade de controles externos dada a amplíssima variedade de procedimentos médicos e de exame existentes, assim como pela existência da figura do terceiro pagador, tirando do consumidor direto do serviço qualquer motivação para se preocupar com os custos do tratamento. Visando conter esse possível aumento extraordinário de custos, as formas de regulação têm optado por mecanismos como contratação com sistemas de capitação e tarifas integrais por diagnóstico (Pérez, 2002: 13).

\section{A Questão da Eqüidade}

A questão da iniqüidade em saúde deve ter como ponto de partida algumas consideraçōes de ordem geral. Em primeiro lugar, a que exatamente se faz referência quando se trata da eqüidade em saúde? De uma forma ampla, pode-se conceituar a iniqüidade como aquela situação em que subsistem fatores, perfeitamente evitáveis, os quais determinam condições de saúde diversas às pessoas. A referência aqui é a fatores como: comportamento prejudicial à própria saúde em que a liberdade de escolha encontra-se restringida, exposição a condições de vida e de trabalho insalubres e estressantes e acesso inadequado à saúde e a outros serviços básicos ${ }^{9}$.

Do ponto de vista do dispêndio social, o ideal seria que, em momentos de crise, esse dispêndio servisse para amenizar o quadro de carências mediante ampliação de seu volume total e per capita, aumentando, do mesmo modo, sua eficiência e progressividade.

No que tange ao primeiro critério, montante total e per capita dos gastos sociais, a facilidade para avaliação - em que pese alguns problemas quanto aos deflatores e/ ou indicadores - é inequívoca e dispensa maiores comentários.

Já no tocante aos dois demais "critérios" impōem-se algumas dificuldades operacionais de monta.

A eficiência da política social pode ser definida, grosso modo, como a utilização mais adequada dos recursos disponíveis, levando-se em conta, sobretudo, o atendimento das populaçóes-alvo. Nesse sentido, e conquanto possa não ser uma definição consensual,

\footnotetext{
${ }^{9}$ Prosperi (2000). Os determinantes das diferenças de saúde inevitáveis seriam: variação biológica natural, comportamento prejudicial para a saúde escolhido livremente e vantagem transitória em condições de saúde de um grupo sobre outros causada pela adoção precoce de uma conduta que melhora a saúde, sempre e quando os outros grupos tenham iguais meios para adotá-la em pouco tempo.
} 
a eficiência poderia, a princípio, ser medida pela relação entre o total de gastos administrativos e os recursos totais carreados para determinado setor. Entende-se que, quanto maior for o montante de recursos em atividades-meio vis-à-vis as atividades-fins, menor o nível de eficiência. Uma observação importante diz respeito à impossibilidade de utilização desse critério para o cotejo entre setores, dadas as peculiaridades institucionais conformadoras de cada atividade (saúde, educação, previdência social e seguro-desemprego). Poderia, no entanto, a não ser que haja algum fato excepcional, servir como parâmetro razoável para comparações entre países e ao longo do tempo, desde que os dados estejam disponíveis.

Em relação ao critério de progressividade, as dificuldades de ordem metodológica são mais substantivas. Delimitar, com razoável grau de precisão, qual a parcela do gasto social apropriada por cada segmento relevante de renda exige disponibilidade de dados e em nível minucioso pouco comuns. Mesmo os países com maior abundância de informações não escapam, para fins de operacionalização do conceito de progressividade, à necessidade de adoção de alguns pressupostos simplificadores. Daí a pouca freqüência com que se encontram tais estudos, dentre os quais podemos mencionar alguns que vão ao encontro do que se pretende evidenciar em relação à eqüidade nas políticas sociais dos países latino-americanos.

Um desses estudos é o realizado por Infante e Revoredo ${ }^{10}$, o qual apontou uma participação de $50 \%$ dos gastos sociais na renda efetiva dos segmentos mais pobres do Chile e Costa Rica, reduzindo-se tal percentual a 26\% para o caso do Uruguai.

Uma das questôes-chave referente às políticas sociais nos países subdesenvolvidos em geral - e particularmente no caso latino-americano - diz respeito à reduzida eqüidade fiscal do financiamento do setor público. Ou seja, à diminuta progressividade das fontes de recursos captados pelo Estado para fazer face ao dispêndio social. Com vistas a diagnosticar tal situação, a Organização Mundial da Saúde (OMS) desenvolveu uma metodologia voltada para avaliar o grau de progressividade das fontes de financiamento do setor de saúde, cujos resultados, para os países latino-americanos, encontram-se expostos abaixo.

Os resultados alcançados por esse estudo, referentes ao ano de 1997, encontramse dispostos na tabela 2 seguinte.

\footnotetext{
${ }^{10}$ Infante, R. \& Revoredo, C. Gasto social y nível de ingreso de las famílias pobres. In: PREALC. Deuda social. Desafio a la equidad. Santiago, Chile, dez. 1993. Apud Bustelo, 1994: 27.
} 
Tabela 2

Índice de Eqüidade na Contribuição Financeira

para 0 Sistema de Saúde

América Latina - Paises Selecionados: 1997

\begin{tabular}{|l|c|}
\hline \multicolumn{1}{|c|}{ Pais } & Índice de Eqüidade \\
\hline Colômbia & 0,992 \\
\hline Uruguai & 0,968 \\
\hline Costa Rica & 0,948 \\
\hline Bolivia & 0,946 \\
\hline Panamá & 0,940 \\
\hline Equador & 0,935 \\
\hline Argentina & 0,934 \\
\hline Venezuela & 0,931 \\
\hline Jamaica & 0,921 \\
\hline México & 0,903 \\
\hline República & 0,892 \\
\hline Dominicana & 0,889 \\
\hline Guatemala & 0,875 \\
\hline Haiti & 0,874 \\
\hline Nicarágua & 0,864 \\
\hline Chile & 0,846 \\
\hline El Salvador & 0,842 \\
\hline Paraguai & 0,834 \\
\hline Honduras & 0,805 \\
\hline Peru & 0,623 \\
\hline Brasil & \\
\hline & \\
\hline
\end{tabular}

Fonte: World Health Organization. The World Health

Report, 2000.

Tal indicador foi construído para variar entre 0 e 1; na medida em que o indicador se aproxime da unidade, melhor é a forma de financiamento de acordo com critérios de repartição adequada do risco associado a este tipo de dispêndio e melhor sua incidência de acordo com o nível de renda dos indivíduos. Entre os vinte países para os quais havia dados disponíveis, o Brasil não só apresentou a última colocação, como também ainda se encontrava bem distanciado do penúltimo colocado.

Essa situação encontra-se relacionada à elevada participação, no caso brasileiro, dos impostos indiretos no montante de recursos públicos totais alocados para o setor saúde.

Em termos mais amplos, a CEPAL desenvolveu uma metodologia visando avaliar em que medida determinados gastos sociais colaboram para melhorar ou tornar mais regressiva a distribuição de renda e chegou a algumas conclusões importantes.

"Al respecto cabe mencionar que la aplicación del índice de desigualdad de Gini a la distribución del gasto social por estrato de ingresos arroja valores de -1 a cero cuando 
la distribución es progresiva y de cero a 1 cuando resulta regresiva, por lo que si aplica a varios países de la región permite calificar a los sectores de acuerdo al carácter del gasto. En la mayoría de los casos dicho índice se ubica entre $-0,20$ y $-0,40$ en la educación primaria y entre $-0,10$ y $-0,20$ en la secundaria, por lo que el gasto es progresivo. Por ende también lo es el gasto total en educación, cuyo índice fluctúa entre $-0,10 y-0,20$, aunque otro de sus componentes, el gasto en educación superior, resulta regresivo, con índices entre 0,20 y 0,40 . Salud y asistencia social resultan claramente progresivos con índices que por lo general se ubican entre $-0,20$ y $-0,30$, mientras seguridad social se calificaría como regresivo por registrar índices de 0,20 a 0,40 ; vivienda presenta comportamientos disímiles en la región y una marcada tendencia a ser más bien regresivo" (CEPAL, 1997: 109-110).

Segundo as estimativas da CEPAL, os gastos com o ensino fundamental e médio encontram-se dirigidos fundamentalmente para as crianças e adolescentes entre cinco e dezessete anos localizados nos quatro primeiros quintis da distribuição de renda per capita, enquanto o gasto com educação superior beneficiaria, essencialmente, os jovens com dezoito a vinte e quatro anos de idade localizados entre o segundo e o quinto quintil da distribuição. Situação semelhante à do gasto com o ensino básico e médio pode ser constatada também para o dispêndio com saúde, estimando-se que esta despesa se concentre fundamentalmente nos quatro primeiros quintis da distribuição de renda per capita.

$\mathrm{Na}$ seqüência, o mesmo estudo observa que, no caso brasileiro, nos primeiros sete anos da década de 1990, o dispêndio com a seguridade social foi o que cresceu com maior intensidade, respondendo por quase todo o crescimento das despesas da área social. Assim, do crescimento total do gasto per capita com a área social, equivalente a US\$130,00, US\$133,00 correspondeu ao aumento do dispêndio com a seguridade social, US\$ 9,00 foi o acréscimo correspondente à área de habitação. Já o setor de saúde observou um incremento de apenas US\$3,00, reduzindo-se em US\$ 16,00 o dispêndio per capita referente à educação.

Quando observamos o que ocorreu na Argentina e no Chile, percebemos uma distribuição bem mais eqüitativa do aumento do gasto social entre as três principais áreas. No Chile, o aumento do gasto com seguridade social respondeu por um terço do incremento total, sendo seguida de perto pelo aumento do gasto com educação, 29\%; os dispêndios com saúde responderam por $21 \%$ da ampliação do gasto social total. $\mathrm{Na}$ Argentina, o predomínio quanto às taxas de crescimento foi do setor de educação, com $30 \%$ de participação no total do crescimento, seguido de perto pela seguridade social (28\%) e pelo incremento dos gastos com saúde (25\%) (CEPAL, 1997: 110).

Já no caso do México, nesse mesmo período, os gastos que apresentam maior progressividade (educação e saúde) explicam a maior parte do crescimento do gasto 
social. Apenas o incremento havido no setor de educação respondeu por cerca de 59\% do aumento total do gasto social entre 1990 e 1997.

Há, portanto, entre os quatro países, uma diferença de ênfase no que toca ao incremento do dispêndio social bastante significativa na primeira metade dos anos 1990. Enquanto no Brasil a "qualidade" do gasto social sofreu nítida deterioração, com redução de seu papel redistributivo. Tal situação tendeu a melhorar de forma modesta nos casos da Argentina e do Chile, havendo, por outro lado, melhoria expressiva da composição da despesa social no México, em virtude da perda de importância relativa da seguridade social e da ampliação do gasto com educação, o qual apresenta característica positiva do ponto de visa distributivo.

Entre os principais fatores que explicam o aumento do gasto com seguridade social nos três primeiros países, destacam-se os reajustes das aposentadorias e pensões, o reconhecimento e a amortização de passivos acumulados em períodos pretéritos, assim como a expansão da cobertura populacional e do tipo de benefícios concedidos (CEPAL, 1997: 111). No caso brasileiro, tais fatores encontram-se intimamente relacionados às mudanças operadas a partir da Constituição de 1988.

\section{Considerações Finais}

Assistimos nos anos 90, na América Latina, a um reforço muito nítido do discurso liberal, o qual já vinha se consolidando como hegemônico nos anos 80 , na esteira das mudanças políticas e ideológicas ocorridas em âmbito mundial e do agravamento do problema inflacionário e do quadro fiscal de grande parte dos países latino-americanos.

A retomada do ideário liberal orientou, em termos concretos, três ordens de transformações de caráter estrutural: i) o processo de reestruturação produtiva; b) o processo de abertura econômica e; c) o processo de reforma do Estado.

Os impactos de tais processos foram extremamente significativos, conduzindo a alteraçôes importantes, notadamente no que tange ao papel do Estado na economia.

Para os países mais desenvolvidos, a retórica e a prática neoliberal caminharam, fundamentalmente, no sentido da privatização de empresas estatais e na redução dos impostos e gastos do governo, mormente na área social. A amplitude e a qualidade dos serviços e benefícios prestados pelo Estado à população levou, segundo a argumentação dos partidos políticos conservadores, ao agravamento do problema do déficit público e da inflação, simultaneamente à perda de eficiência da economia ao induzir os trabalhadores em geral, e certos grupos sociais em particular, à acomodação frente ao processo produtivo. Tornou-se de certa forma comum a referência aos grupos de pessoas que há duas ou três gerações sobreviviam às custas da assistência social. 
Já no caso dos países subdesenvolvidos, em particular os latino-americanos, a retórica e a prática parecem divergir, relativamente aos outros países capitalistas, no que se refere ao âmbito das políticas sociais. A queixa dos liberais em relação à intervenção do Estado na economia tende a se dirigir para o setor produtivo e não para a área social. Devido a características próprias do seu processo de industrialização, a maior parte dos países latino-americanos, contou com a participação decisiva do Estado na montagem do parque industrial, seja investindo diretamente, seja subsidiando, por meio de diversos mecanismos, a iniciativa privada. Nesse contexto, a participação do setor público na área social, notadamente no caso brasileiro, acabou relegada a segundo plano. Daí a retórica liberal, em nosso meio, dirigir-se, basicamente, para a questão da privatização e desregulamentação da economia, enfatizando-se a necessidade de maiores dispêndios por parte do governo na política social. Ou seja, entre outras propostas de alteração das políticas públicas em curso até então, o novo discurso dominante vai apelar insistentemente para que se reoriente de forma rápida a atuação do Estado, deslocando-o da órbita produtiva em favor de uma intervenção mais incisiva na área social, corrigindo-se, dessa forma, um dos principais vieses do Estado desenvolvimentista.

Não há como deixar de reconhecer os resultados positivos alcançados pelas reformas dos anos 1990 nos países latino-americanos quanto a duas das principais variáveis macroeconômicas: inflação e PIB. Entretanto, o exame dos impactos de tal desempenho sobre outros indicadores no campo econômico e social revelam que a difusão dos benefícios associadas à maior estabilidade e maior crescimento nos anos 90 não se fizeram tão amplos como a princípio se esperaria.

A estratégia de maior abertura comercial combinada com valorização cambial só poderia ser viabilizada mediante maior afluxo de capitais externos, tendo em vista o impacto negativo sobre o saldo em conta corrente, tornando-se indispensável a elaboração de políticas consistentes para sensibilizar os investidores externos.

Os impactos de tais políticas revelaram-se fortemente instabilizadores do ponto de vista do crescimento econômico, obrigando, em boa parte dos países, a profundas inflexôes nas políticas de demanda agregada, ao mesmo tempo em que permitiu desviar parcela expressiva da demanda doméstica para as importaçôes e deprimir as vendas externas. A contribuição de tal estratégia para o aumento do desemprego revelou-se inequívoca.

Não há como deixar de constatar a discrepância entre o discurso e a prática dos países latino-americanos, a qual encontra-se relacionada, de um lado, à expansão dos encargos financeiros e de alguns outros gastos alheios aos controles das autoridades governamentais - a exemplo dos previdenciários - e às resistências políticas, legítimas 
e ilegítimas, que se antepõem a qualquer proposta concreta relacionada a cortes nos dispêndios públicos.

Todavia, tais resultados positivos para a maioria dos países, conjugado com a expansão do PIB no mesmo período não foram suficientes para reverter de forma importante os principais indicadores de pobreza da região.

É importante notar que a maior parte do aumento de renda das famílias deve-se à maior densidade de utilização da mão-de-obra familiar - sobretudo no setor de serviços e trabalho por conta própria -, sem que a média de rendimentos da força de trabalho tenha apresentado desempenho compatível.

Ademais, a diminuição no percentual de domicílios pobres acompanhada de seu crescimento em termos absolutos mostra que o crescimento econômico observado no período permitiu apenas que a pobreza crescesse mais lentamente que a população como um todo, o que está a indicar que o redirecionamento das prioridades de políticas públicas e das políticas redistributivas não se efetivaram no período.

O fato é que as reformas liberalizantes apregoadas como única alternativa para a estabilidade e crescimento econômico dos países latino-americanos não se mostraram capazes de proporcionar, na maioria dos casos, estabilidade nas taxas de crescimento e redução consistente da pobreza e principalmente da desigualdade social.

Conquanto os grupos mais pobres tenham sido beneficiados pela redução na perda operada pelo imposto inflacionário, a lógica do processo de ajuste econômico findou por beneficiar mais fortemente os estratos de renda média e alta, mediante o acesso mais amplo aos bens importados, viagens internacionais e maiores facilidades para evasão de divisas.

A intensa dependência dos fluxos de capitais externos e a instabilidade inerente aos mercados internacionais colocaram em xeque o modelo de desenvolvimento baseado na maior abertura da economia, impondo aos países latino-americanos a busca de estratégias alternativas que até então não se configuraram concretamente.

Enquanto isso se assiste a insistência num discurso que prega o aprofundamento das reformas liberais como opção exclusiva para a solução dos problemas atuais, sem que a implementação dessas políticas em períodos pretéritos tenha proporcionado bases consistentes para a retomada do crescimento econômico e, sobretudo, melhorias significativas no quadro social, com a reversão do quadro de renda extremamente concentrada que caracteriza a América Latina.

Os argumentos ainda esgrimidos quanto ao papel determinante do crescimento econômico e da estabilidade monetária como promotores de melhorias na situação social não encobrem o fato de que, ao longo dos anos 90, mesmo observando-se estas duas situações, houve aumento da pobreza e da concentração de renda na América 
Latina, sem que as políticas sociais se revelassem capazes de dar uma resposta adequada a essa situação. Isto ocorreu, sobretudo, tendo em vista as deficiências quanto ao aspecto de eqüidade. Ou seja, conquanto baseadas em metas e princípios louváveis, a aplicação de tais princípios deixou muito a desejar, mantendo-se inalterado ou pouco modificados grande parte dos problemas historicamente experimentados pelos países latino-americanos. Destacam-se, entre as medidas que alcançaram alguma efetividade, aquelas elaboradas/implementadas sob patrocínio do Banco Mundial.

Todavia, o que se observou no período sob análise foi, no máximo, uma resposta tímida das políticas sociais ao quadro de carências vivido pela população da América Latina nos anos 1990. As reformas implementadas na área de saúde, com sua preocupação na focalização, descentralização e busca de um ambiente institucional mais adequado à eficiência não foram capazes de promover melhorias significativas quanto ao acesso aos serviços de saúde para a maioria da população.

\section{Bibliografia}

AVELINO FILHO, George, BROWN, David S. \& HUNTER, Wendy A. Globalization, democracy and social spending in Latin America, 1980-1997. mimeo, 2002.

BANCO MUNDIAL. Reforma do sistema de saúde na América Latina e no Caribe e o Banco Mundial. Mimeo, 2002.

BUSTELO, Eduardo. Hood Robin: ajuste e eqüidade na América Latina. In: Planejamento e Politicas Públicas. n. 11, jun/dez, 1994, p. 5-47.

CAVALCANTI, Soraya Araújo Uchoa. Reforma do Estado e políticas sociais no Brasil. In: Texto para Discussão, Recife, n. 1, 2001.

CEPAL. División de Dessarollo Social. Modelos de desarrollo, papel del estado y políticas sociales: nuevas tendencias en América Latina. 1995.

CEPAL. Eqüidade, desenvolvimento e cidadania. Rio de Janeiro: Campus/ CEPAL, 2002.

CEPAL. Panorama social da América Latina. Santiago: CEPAL, vários anos.

COHN, Amélia \& ELIAS, Paulo Eduardo Mangeon. Eqüidade e reformas na saúde nos anos 90. In: Cadernos de Saúde Pública, 18 (Suplemento), 173-180, 2002.

$\mathrm{COHN}$, Amélia. Gastos sociais e políticas sociais nos anos 90: a persistência do padrão histórico de proteção social brasileiro. In: Anais do XXIV Encontro Anual da Associação Nacional de Pós-Graduação em Ciências Sociais (ANPOCS), GT03. Petrópolis, 2000.

COMINETTI, Rosella \& GROPELLO, Emanuela Di. El gasto social en América Latina: un examen cuantitativo and cualitativo. In:Cuadernos de la CEPAL. 
Santiago de Chile, Comissión Económica para América Latina y el Caribe (CEPAL), v. 71, 1994.

COMINETTI, Rosella \& RUIZ, Gonzalo. Evolución del gasto público social en America Latina: 1980-1995. In: Cuadernos de la CEPAL. Santiago de Chile, Comissión Económica para América Latina y el Caribe (CEPAL), v. 80, 1998.

COSTA, Nilson do Rosário. Inovação política, distributivismo e crise: a política de saúde nos anos 80 e 90. In: Dados, v. 39. n. 3. Rio de Janeiro, 1996.

COSTA, Nilson do Rosário. Políticas públicas, justiça distributiva e inovação-saúde e saneamento na agenda social. São Paulo: Hucitec, 1998.

COSTA, Nilson do Rosário. Política social e ajuste macroeconômico. In: Cadernos de Saúde Pública. Rio de Janeiro, 18 (Suplemento): 13-21, 2002.

DEININGER, Klaus \& SQUIRE, Lyn. New Data Set Measuring Income Inequality. In: The World Bank Economic Review, v. 10, n.3, 565-91. IBRD/ World Bank, 1996.

DRAIBE, Sônia Miriam. A reforma dos programas sociais brasileiros: panoramas e trajetórias. In: Anais do XXIV Encontro Anual da Associação Nacional de PósGraduação em Ciências Sociais (ANPOCS), GT12. Petrópolis, 2000.

DRAIBE, Sônia. A proteção social após vinte anos de experimentação reformista. In: Taller Inter-Regional Protección Social en una Era Insegura: un Intercambio Sur-Sur sobre Politicas Sociales Alternativas en Respuesta a la Globalización. Santiago: Programa de las Naciones Unidas para el Desarrollo, 2002.

FLEURY, Sonia. Políticas e sistemas sociais em transformação na América Latina. In: Socialis-Revista Latino-Americana de Política Social, Buenos Aires, n. 1, oct, 1999.

FLEURY, Sonia. Politicas sociais e democratizaçāo do poder local. Mimeo, 2002.

KAUFMAN, Robert \& SEGURA, Alex. Globalization, domestic politics and social spending in Latin America: a time-series cross-section analysis, 1973-1997. In: World Politis, v. 53, 2001, p. 553-587.

LABRA, Maria Eliana. Padrões de formulação de políticas de saúde no Chile no século XX. In: Dados. Rio de Janeiro, v. 43, n. 1, 2000.

MISOCZKY, Maria Ceci. Informaçôes sobre sistemas de saúde. (http://www.ufrgs.br/ pdgs/sistemas.htm - capturado em 25/07/2003).

MUSGROVE, P. Public and private roles in health. Theory and financing patterns. Washington, D.C.: 1996. 79p. (The World Bank Discussion Paper, n. 339)

PÉREZ, Iván Jaramillo. Tendencias en la reorganización de los sistemas de salud. 16 p. (http://www.medicina.unal.edu.co/ist/revistasp/v4n1/v4n1e2.htm - capturado em $10 / 12 / 2002$ ) 
PINHEIRO, Vinícius C. Modelos de desenvolvimento e políticas sociais na América Latina em uma perspectiva histórica. In: Planejamento e Políticas Públicas. n. 12, jun./dez. 1995, p. 63-88.

PROSPERI, Jorge Luis (2000). Equidad y reforma del sector salud. División de Desarrollo de Sistemas y Servicios de Salud. OPS/OMS Venezuela. (http:// www.opas.org.br/servico/Arquivos/Sala1540.pdf - capturado em 28/07/2003) 